\title{
SANTA FE WORKSHOP ABSTRACTS ${ }^{1}$
}

\section{REFINING ESTIMATES OF ${ }^{10}$ Be AND ${ }^{26}$ Al PRODUCTION RATES}

\section{PAUL BIERMAN, ${ }^{2}$ PATRICK LARSEN, ${ }^{2}$ ERIK CLAPP ${ }^{3}$ and DOUGLAS CLARK ${ }^{4}$}

We have taken a variety of approaches to refine the existing ${ }^{10} \mathrm{Be}$ and ${ }^{26} \mathrm{Al}$ production rate estimates of Nishiizumi et al. (1989), including measuring nuclide abundances on boulders and bedrock surfaces exposed on the relatively well-dated Laurentide moraine, making altitude and latitude corrections using different, now currently accepted protocols, and modeling the effect of changing geomagnetic field strength on production rates over time.

In north-central New Jersey, we collected 16 samples of quartzite and gneiss from striated and/or glacially molded outcrops and large glacial erratics on or just behind the terminal moraine of the Laurentide ice sheet (Larsen 1995). The exposure age of the moraine is estimated to be $\sim 21.5 \mathrm{ky}$ sidereal years on the basis of several limiting ${ }^{14} \mathrm{C}$ ages. The calibration of these ${ }^{14} \mathrm{C}$ ages is based on the recommendations of Stuiver et al. (1991). Average concentrations and standard errors of the mean of $1.37 \pm 0.04 \times 10^{5}(\mathrm{n}=12)$ atoms $\mathrm{g}^{-1} \mathrm{SiO}_{2}$ for ${ }^{10} \mathrm{Be}$ and $8.03 \pm 0.29 \times 10^{5}(\mathrm{n}=14)$ atoms $\mathrm{g}^{-1} \mathrm{SiO}_{2}$ for ${ }^{26} \mathrm{Al}$ can be used to calculate integrated sea level, high-latitude production rates and associated standard errors of the mean of $5.17 \pm 0.15$ and $30.40 \pm 1.01$ atoms $\mathrm{g}^{-1} \mathrm{yr}^{-1}$ for ${ }^{10} \mathrm{Be}$ and ${ }^{26} \mathrm{Al}$, respectively. The isotope abundances show no significant variation between boulder and outcrop sample locations and quartzite and gneiss sample lithologies, implying that the effects of erosion and till cover are negligible. We have scaled these abundance data to sea level and high latitude using the neutron data of Lal (1991) following the finding by Brown et al. (1995) that muon production is insignificant; however, because our samples were collected at relatively high latitude $\left(41^{\circ}\right)$ and low altitude (300 $\mathrm{m})$, the choice of scaling protocol is unimportant. The integrated production rates calculated over the past $21.5 \mathrm{ky}$ are $c a .18 \%$ lower than previously determined integrated production rates over the $11 \mathrm{ky}$ (Nishiizumi et al. 1989) and $50 \mathrm{ky}$ (Nishiizumi et al. 1991b) time frames.

Comparing these three different production rate estimates is not straightforward. Each was calculated from samples exposed for varying lengths of time at different altitudes and latitudes. Scaling the lower-latitude, higher-altitude measurements from the Sierra Nevada and Meteor Crater to sea level and high latitude involves choosing an effective geomagnetic latitude for the duration of exposure, determining the contribution of muons to ${ }^{10} \mathrm{Be}$ and ${ }^{26} \mathrm{Al}$ production as a function of altitude and latitude, and determining how instantaneous production rates have changed over the duration of exposure at each site.

We find that by assuming muon production is inconsequential at sea level (Brown et al. 1995); scaling the three data sets for spallation only, and incorporating a geomagnetically driven production rate forcing model (Clark et al. 1995; Clapp and Bierman, in review), the three different production rate estimates can be reconciled to within several percent if the exposure age of the Sierra Nevada calibration sites is taken to be $13.5 \mathrm{ky}$ as suggested by Clark et al. (1995). Although such agreement is promising, additional data must be gathered to test these findings. Until those data have been gathered, nuclide production rates as a function of altitude, latitude and exposure duration will remain a significant uncertainty in the interpretation of nuclide abundance data.

${ }^{1}$ See Bibliography on pp. 142-147 for references not separately provided in following abstracts.

${ }^{2}$ Department of Geology, University of Vermont, Burlington, Vermont 05405 USA

${ }^{3}$ School of Natural Resources, University of Vermont, Burlington, Vermont 05405 USA

${ }^{4}$ Department of Geological Sciences, University of Washington, Seattle, Washington 98195 USA 


\section{AN ANTARCTIC PERSPECTIVE ON IN-SITU COSMOGENIC NUCLIDE PRODUCTION}

\section{EDWARD J. BROOK, ${ }^{1}$ ERIK T. BROWN, ${ }^{2}$ MARK D. KURZ, ${ }^{3}$ GRANT RAISBECK ${ }^{4}$ and FRANÇOISE YIOU 4}

Long-term average production rates of some nuclides can be constrained by examining slowly eroding, old rock surfaces. At steady state with respect to production and radioactive decay, production rates are simply calculated from concentration data (e.g., $\mathrm{P}=\mathrm{N} \lambda)$, as long as erosion is negligible (Brook et al. 1995) The possibility that erosion is non-negligible makes these production rates minimum values. Examination of our and other published ${ }^{26} \mathrm{Al}$ data (half-life $7.2 \times 10^{5} \mathrm{yr}$ ) from a total of 15 Antarctic rock surfaces with ${ }^{10} \mathrm{Be}$ exposure ages older than $2 \mathrm{Ma}$ (and therefore model erosion rates $<\sim 7 \mathrm{~cm} / \mathrm{Ma}$ ) yields ${ }^{26} \mathrm{Al}$ production rates that agree well with the published Sierra Nevada rates (Nishiizumi et al. 1989), assuming the altitude/latitude scaling of Lal (1991). The samples span an altitude range of 1380 to $2650 \mathrm{~m}$ and at each sample altitude the calculated production rates agree with the scaled Sierra Nevada rates within $\sim 10 \%$. The sea level production rate derived from the data (Lal 1991) is $35 \pm 2$ at/g/yr, close to the predicted value (Lal 1991) of $37 \mathrm{at} / \mathrm{g} / \mathrm{yr}$. These observations suggest that the long-term average ${ }^{26} \mathrm{Al}$ production rate is not higher than, and is probably close to, the value determined for glaciated bedrock in the Sierra Nevada exposed over the last $\sim 11$ $\mathrm{ka}^{2}$. The results also imply that the scaling factors (Lal 1991) are accurate within the latitude and altitude range considered here (excepting the possibility of compensating errors). As there is no reason to expect temporal variations in the ${ }^{26} \mathrm{Al} /{ }^{10} \mathrm{Be}$ production ratio, the long-term ${ }^{10} \mathrm{Be}$ production rate is also probably close to the Sierra Nevada rate (Nishiizumi et al. 1989). These conclusions are similar to those of Nishiizumi (this issue).

We have also collected two 1-1.5 m drill cores in Antarctic sandstone bedrock to examine the depth dependence of ${ }^{10} \mathrm{Be},{ }^{26} \mathrm{Al}$, and ${ }^{3} \mathrm{He}$ production. ${ }^{10} \mathrm{Be}$ and ${ }^{26} \mathrm{Al}$ profiles from one core were reported previously (Brown et al. 1992). Both cores have exponential profiles; scale lengths are close to expected values and are $152 \pm 5$ and $145 \pm 5 \mathrm{~g} / \mathrm{cm}^{2}$ for ${ }^{10} \mathrm{Be}$ and $153 \pm 13$ and $152 \pm 5 \mathrm{~g} / \mathrm{cm}^{2}$ for ${ }^{26} \mathrm{Al}$. Contrary to the calculations of Nishiizumi et al. (1989), these data indicate that muons produce $<1$ $3 \%$ of total ${ }^{10} \mathrm{Be}$ and ${ }^{26} \mathrm{Al}$ at the altitudes and latitude of these cores, consistent with previous conclusions (Brown et al. 1995) based on a depth profile of ${ }^{10} \mathrm{Be}$ at low altitude near the equator.

The situation for ${ }^{3} \mathrm{He}$ is more complicated. One of the two cores exhibits an exponential decrease in cosmogenic ${ }^{3} \mathrm{He}$ with a scale length of $\sim 150 \mathrm{~g} / \mathrm{cm}^{2}$. The second has a distinctly higher scale length, $227 \pm 14 \mathrm{~g} / \mathrm{cm}^{2}$, over a similar depth interval. Studies of different size quartz grains in each core show that the discrepancy, which can be thought of as "extra ${ }^{3} \mathrm{He}$ " at depth, or loss of ${ }^{3} \mathrm{He}$ at the surface, is not an artifact of diffusion. It also does not appear to be caused by the presence of a non-cosmogenic ${ }^{3} \mathrm{He}$ component. Production of ${ }^{3} \mathrm{He}$ by muons is a remaining possibility. A model that includes the processes of erosion, diffusion, and ${ }^{3} \mathrm{He}$ production by neutrons and muons can approximately reproduce the observed profile with reasonable parameters, if exposure times are very long (e.g., of order $20 \mathrm{Ma}$ or greater), and if production of muons is $\sim 10 \%$ of total production at $1700 \mathrm{~m}$. While we are uncertain if this explanation of our data is correct, our observations suggest that further investigation of production rates of ${ }^{3} \mathrm{He}$ due to muon interactions is warranted.

${ }^{1}$ Graduate School of Oceanography, University of Rhode Island, Narragansett, Rhode Island 02882 USA

${ }^{2}$ LLO, University of Minnesota, Duluth, Minnesota 55812 USA

${ }^{3}$ Woods Hole Oceanographic Institution, Woods Hole, Massachusetts 02543 USA

${ }^{4}$ CSNSM, Bâtiment 108, Campus Orsay 91405 France 


\title{
DIRECT EXAMINATION OF TERRESTRIAL COSMOGENIC NUCLIDE PRODUCTION RATES OF ${ }^{10} \mathrm{Be},{ }^{3} \mathrm{He}$ AND ${ }^{3} \mathrm{H}$
}

\author{
ERIK T. BROWN, ${ }^{1,2}$ THOMAS W. TRULL, ${ }^{3}$ PHILIPPE JEAN-BAPTISTE, ${ }^{4}$ \\ DIDIER L. BOURLĖS, ${ }^{1}$ GRANT M. RAISBECK ${ }^{1}$ and FRANÇOISE YIOU ${ }^{1}$
}

We have determined production rates of ${ }^{10} \mathrm{Be},{ }^{3} \mathrm{He}$, and ${ }^{3} \mathrm{H}$ in tanks of water exposed for a period of 15 months at a range of altitudes $(620 \mathrm{~m}, 3810 \mathrm{~m}$, and $4745 \mathrm{~m})$ in the French Alps. Measurements of ${ }^{3} \mathrm{He}$ and ${ }^{3} \mathrm{H}$ were undertaken by static mass spectrometry at Laboratoire de Modelisation du Climat et de l'Environnement in Saclay, France, while ${ }^{10} \mathrm{Be}$ determinations were made at the Tandetron Accelerator Mass Spectrometry Facility in Gif-sur-Yvette, France. Corrections were made for low levels of ${ }^{10} \mathrm{Be}$ and ${ }^{3} \mathrm{H}$ present in the water, for incomplete degassing of atmospheric $\mathrm{He}$, and for production of the three nuclides within the tanks in the laboratory before and after installation at altitude. Further minor corrections were made for self-shielding within the tanks and for skyline shielding by local topography. Our results indicate production ratios for oxygen spallation of $\sim 2: 1$ for ${ }^{3} \mathrm{He}:{ }^{3} \mathrm{H}$ and $\sim 20: 1$ for $\left({ }^{3} \mathrm{He}+{ }^{3} \mathrm{H}\right):{ }^{10} \mathrm{Be}$. Strategies for application of our production rates to longer time periods and other locations, as well as to specific mineral phases, will be discussed.

${ }^{1}$ CSNSM, CNRS-IN2P3, F-91405, Campus Orsay, France

${ }^{2}$ Large Lakes Observatory, University of Minnesota, Duluth, Minnesota 55812 USA

${ }^{3}$ Antarctic CRC, University of Tasmania, GPO BOX 252c, Hobart, Tasmania 7001 Australia

${ }^{4} \mathrm{LMCE}, \mathrm{CEA}-$ Saclay, F-91191 Gif-sur-Yvette Cedex, France

\section{COSMO-CALIBRATE: A PROGRAM FOR CALIBRATING COSMOGENIC EXPOSURE AGES}

\section{ERIK CLAPP and PAUL BIERMAN}

School of Natural Resources and Department of Geology, University of Vermont, Burlington, Vermont 05401 USA

In order to account for geomagnetically induced changes in cosmogenic nuclide production rates in situ, and thereby increase the potential accuracy of exposure age dating, we have developed a numerical model that generates geomagnetically calibrated exposure ages. Currently accepted, model-age calculations are based on time-averaged production rates. Use of time-averaged production rates bay introduce systematic errors $>20 \%$ in exposure ages causing cosmogenically dated events to be correlated incorrectly with events dated by other means (Clark et al. 1995). Applying our model to existing nuclide abundance data generally increases calculated exposure ages (Fig. 1), supports the ${ }^{10} \mathrm{Be}$-based assertion of Gosse et al. (1995) that a glacial advance in the Rocky Mountains may have occurred during the Younger Dryas, and most importantly, reconciles three apparently disparate production rate estimates for ${ }^{26} \mathrm{Al}$ and ${ }^{10} \mathrm{Be}$.

We have created a computer program (COSMO-CALIBRATE) that uses generally accepted geomagnetic paleointensity records (Meynadier et al. 1992; McElhinny and Senanayake 1982) and empirical relationships to account for cosmogenic isotope production rate variations over the last $140 \mathrm{kyr}$. Magnetic field strengths are converted to apparent paleolatitudes using the formulation of Nishiizumi et al. (1989) after which instantaneous production rates are calculated using the third degree polynomial of Lal (1991). Muon contribution is currently assumed to be minimal, as suggested by Brown et al. (1995). Samples exposed at lower latitudes and high altitudes will have experienced greater production rate variation (Fig. 2). 
Our program calculates instantaneous ${ }^{10} \mathrm{Be}$ and ${ }^{26} \mathrm{Al}$ production rates at any given sample site (altitude and latitude) and outputs both geomagnetically calibrated and uncalibrated exposure ages from sample isotopic abundance data. Calibration, such as we propose, will likely increase the accuracy of exposure ages and once verified by additional data, may allow for more robust cosmogenic dating and correlation of relatively brief geomorphic and climatic events. Our program is available as userfriendly, compiled Macintosh code by anonymous ftp from beluga. uvm. edu.

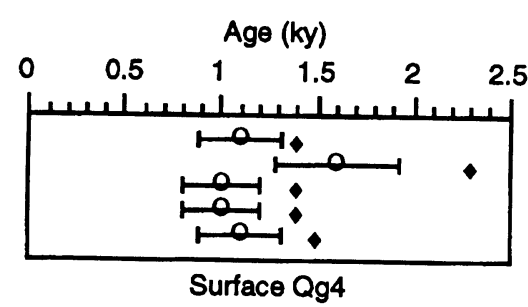

Fig. 1. Calibrated ${ }^{10} \mathrm{Be}$ exposure ages from COSMO-CALIBRATE 1.7 (diamonds) and uncalibrated ${ }^{10} \mathrm{Be}$ exposure ages (Bierman et al.) calculated using production rates of Nishiizumi et al. (1989), for 11,000 cal yr BP (open circles).

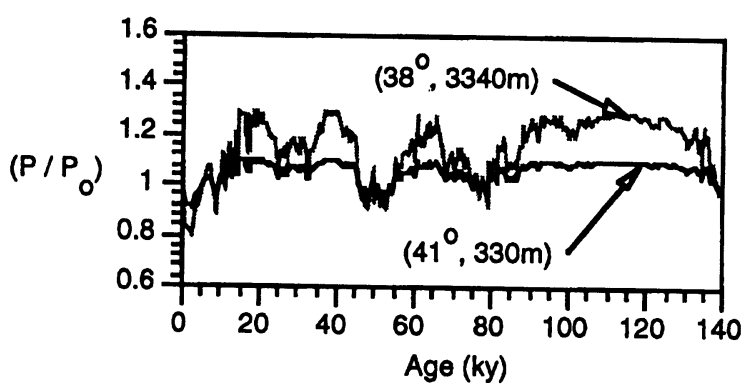

Fig. 2. Relative instantaneous production rates calculated by COSMO-CALIBRATE for two study sites: Sierra Nevada $\left(38^{\circ}\right.$, $3340 \mathrm{M})$ and the Laurentide Terminal Moraine $\left(41^{\circ}, 330 \mathrm{~m}\right)$

\section{${ }^{10}$ Be AND ${ }^{26}$ Al PRODUCTION RATES AND A REVISED GLACIAL CHRONOLOGY
FOR THE SIERRA NEVADA}

\section{DOUGLAS H. CLARK, ${ }^{1}$ PAUL R. BIERMAN ${ }^{2}$ and ALAN R. GILLESPIE ${ }^{3}$}

New ${ }^{14} \mathrm{C}$ ages for Sierra Nevada deglaciation suggest that currently accepted late-Pleistocene production rates of in-situ cosmogenic ${ }^{10} \mathrm{Be}$ and ${ }^{26} \mathrm{Al}$ are $\sim 20 \%$ too high because the assumed age of exposure is too young. The original production rates for the isotopes were calibrated based on measurements of glacially polished granite from the Sierra Nevada, assumed to have been deglaciated $\sim 11,000$ calibrated (or sidereal) years ago (11,000 cal yr BP) (Nishiizumi et al. 1989). This exposure age was estimated from minimum-limiting conventional radiocarbon ages of $\sim 10,000{ }^{14} \mathrm{C}$ yr BP for basal bulk sediments from two sites, a lake and a meadow, dammed behind Tioga (last late-Wisconsin maximum) recessional moraines (Adam 1967; Mezger and Burbank 1986).

Calibrated ages (Bard et al. 1990; Stuiver and Reimer 1993) of 12 new ${ }^{14} \mathrm{C}$ dates, of basal or nearbasal lake sediments from cores of ten postglacial lakes, show instead that Sierra Nevada deglaciation was underway by $16,000-19,000 \mathrm{cal}$ yr BP $\left(\sim 13,500-16,000{ }^{14} \mathrm{C}\right.$ yr BP $)$ and that the range was effectively deglaciated before $\sim 13,100 \mathrm{cal}$ yr BP $\left(11,190{ }^{14} \mathrm{C}\right.$ yr BP) (Clark et al. 1995; Clark and Gillespie, in press). The coring sites all lie inside the maximum Tioga ice limits, as do the two cited by Nishiizumi et al. (1989), and thus provide minimum ages for onset of deglaciation. The highest sites near the crest of the range, however, provide minimum ages for complete retreat of Tioga glaciers and thus minima for the exposure age of sites sampled by Nishiizumi et al. for calibration. The highest lakes we cored, in the headwaters of Bishop Creek, are formed behind moraines of the Recess Peak advance, which ended before 13,100 cal yr BP (Clark and Gillespie, in press). We have 
mapped and correlated Recess Peak moraines along the crest of the Sierra from southern to northern limits of the advance, and find that all calibration sites of Nishiizumi et al. lie downstream from Recess Peak moraines in those drainages. Thus, our minimum age control for the Recess Peak advance in Bishop Creek also provides a firm minimum age for exposure of the calibration sites. The accuracy of the AMS ${ }^{14} \mathrm{C}$ dates from the Bishop Creek cores is supported by: 1) other dates from higher in the same cores that are internally consistent; 2) parallel dates between adjacent gyttja and macrofossils in the cores that are indistinguishable within 1-sigma analytic error (typically $<1 \%)$; 3) similar findings in dates of cores from other areas that also are internally consistent; and 4) absence of sources of contamination, especially "old" carbon, in the drainage basins upstream from the lakes. These observations substantiate the stability of carbon in high Sierran lake basins. Together, the new limiting ${ }^{14} \mathrm{C}$ dates indicate that Tioga deglaciation occurred at least $2000 \mathrm{cal}$ yr before 11,000 cal yr BP.

Recalculating the production rates using the formulation and measured abundances of Nishiizumi $e t$ al. (1989) but assuming the sites were deglaciated 13,500 cal yr BP yields sea-level, high-latitude production rates that are $\sim 20 \%$ lower than in the original calibration for both isotopes. This difference agrees within several percent of an independent late-Pleistocene calibration from the Laurentide terminal moraine in New Jersey (Larsen 1995), if appropriate latitudinal scaling and the affects of geomagnetic field-strength fluctuations on production rates are considered (Clark et al. 1995; Clapp and Bierman 1995). Our results emphasize the need for accurate, independent age control and geologic context as primary foundations for production-rate calibrations of cosmogenic nuclides.

\section{ADDITIONAL REFERENCES}

Adam, D. P. 1967 Late Pleistocene and recent palynology in the central Sierra Nevada, California. In Cushing, E. J. and Wright, H. E., Jr., eds., Quaternary Paleoecology. New Haven, Yale University Press: 275-301.

Mezger, L. and Burbank, D. 1986 The glacial history of the Cottonwood Lakes area, southeastern Sierra Nevada. Geological Society of America, Abstracts with Programs 18: 157.

${ }^{1}$ Department of Geological Sciences, University of Washington, Seattle Washington 98195 USA

${ }^{2}$ Department of Geology, University of Vermont, Burlington, Vermont 05405 USA

${ }^{3}$ Department of Geological Sciences, University of Washington, Seattle, Washington 98195 USA

\section{PLANS FOR CALIBRATION OF THE COSMIC RAY FLUX OVER THE PAST 500,000 YEARS USING VOLCANIC ROCK}

\section{A. DUNNE, D. ELMORE and P. SHARMA}

PrimeLab, Purdue University, West Lafayette, Indiana, USA

While recent measurements of neutron fluxes can be combined with nuclear reaction data using Monte Carlo simulation techniques to predict the current production rates of cosmogenic nuclides, such techniques cannot be used to explore the past history of the cosmic ray flux (CRF). Although certain effects are fairly well understood or modeled, such as short-term cycling of the CRF at the surface of the Earth in response to variations in the Earth's magnetic field, other variations are not as well categorized. While some ice cores and similar historical record-keepers provide some insight into the past, it is the intent of this project to calibrate the method of ${ }^{36} \mathrm{Cl}$ rock exposure dating, and hence the cosmogenic production rates, back through 500 ka by comparing the ${ }^{36} \mathrm{Cl}$ concentrations with ${ }^{40} \mathrm{Ar} /{ }^{39} \mathrm{Ar}$ data in collected samples from the central Andes. 
The central Andes is an ideal location for a study such as this. This hyper-arid and isolated environment offers samples that have remained undisturbed and effectively uneroded in a location that has had little or no water or vegetation cover. In addition, the high altitude of the region insures very high nuclide concentrations. The effectively instantaneous creation of the lava flows aids in correlating the ${ }^{40} \mathrm{Ar} /{ }^{39} \mathrm{Ar}$ to the measured ${ }^{36} \mathrm{Cl}$ concentrations, and the long-term development of the volcano by successive flows will provide a moderately wide span of dates for the calibration. As an additional incentive, Tata Sabaya, the specific volcano to be studied, underwent a cone collapse that resulted in an easily identifiable debris flow. This extra "instantaneous" event provides another point on the calibration curve.

When combined with the existing calibration data, which focus on more recent time periods, these new data should provide a broader perspective on long-term variations in the CRF. Analysis will incorporate Monte Carlo neutron transport simulations to account for rock geometry and water content in addition to the standard scaling factors such as geometric shielding, altitude and latitude variations, and erosion effects. With the higher frequency variations from magnetic field fluctuations effectively averaged out after only a few cycles, any long-term variations in the CRF, and hence, the radioisotope production rates, will be identifiable, making the results of the project useful to any method or procedure that relies on cosmogenic nuclides.

\section{PRODUCTION RATE OF IN-SITU COSMOGENIC ${ }^{10}$ Be IN QUARTZ AT HIGH ALTITUDE AND MID LATITUDE}

\section{J. GOSSE}

EES-1, Los Alamos National Laboratory, Los Alamos, New Mexico 87545 USA

and

\section{J. KLEIN}

Department of Physics, University of Pennsylvania, Philadelphia, Pennsylvania 19104 USA

Several considerations must be made when attempting to empirically calibrate a cosmogenic nuclide time scale to the calendric time scale. The sampled surface should not have been buried or eroded during exposure, the initial cosmogenic concentration of the nuclide must be zero (i.e., no inheritance from prior exposure), there should be no significant shielding or geometry problems, and the lithology must be suitable. The duration of the exposure of the surface must also be accurately known. Finally, the geomagnetic latitude and duration at which calibrations are done should be taken into account because at some latitudes even a small uncertainty in geomagnetic latitude can produce a large uncertainty in the production rate. For calibration sites having $<10 \mathrm{kyr}$ exposure, the uncertainty in geomagnetic latitude due to pole position secular variation may be a factor because the dipole axis may not have been geocentric. If the change in production rate due mainly to geomagnetic field intensity variation is the focus, it may be useful to concentrate our measurement of production rates at sites within the latitudinal zone $\left(\sim 15^{\circ}-45^{\circ}\right)$ where these geomagnetic uncertainties have the most significant effects.

We have sampled 10 boulders from the inner Titcomb Basin moraine in the Wind River Range, Wyo$\operatorname{ming}\left(3.3 \mathrm{~km}, 43^{\circ} \mathrm{N}\right)$, which has been correlated to the Temple Lakes moraine, dated by Zielinski and Davis (1987) and Davis (1994), at $\sim 11.4$ to $11.7{ }^{14} \mathrm{C}$ kyr. The site production rate of ${ }^{10} \mathrm{Be}$ in quartz assuming $12.9 \mathrm{cal} \mathrm{kyr}$ (Stuiver and Reimer 1993) for the moraine age is 51.7 atoms $\cdot \mathrm{g}^{-1} \mathrm{yr}^{-1}, 53.6$ atoms $\cdot \mathrm{g}^{-1} \mathrm{yr}^{-1}$ if adjustments are made for the effects of snow and one of the ten samples is considered an outlier. The production rate at sea level, high latitude (using Lal 1991) is ca. 5.5 atoms $\cdot \mathrm{g}^{-1}$ 
$\mathrm{yr}^{-1}$ based on nine samples and adjusted for snow cover. Considering the uncertainties in the exposure time, snow density, and muonic scaling, the uncertainty in this production rate is $\pm 12 \%$.

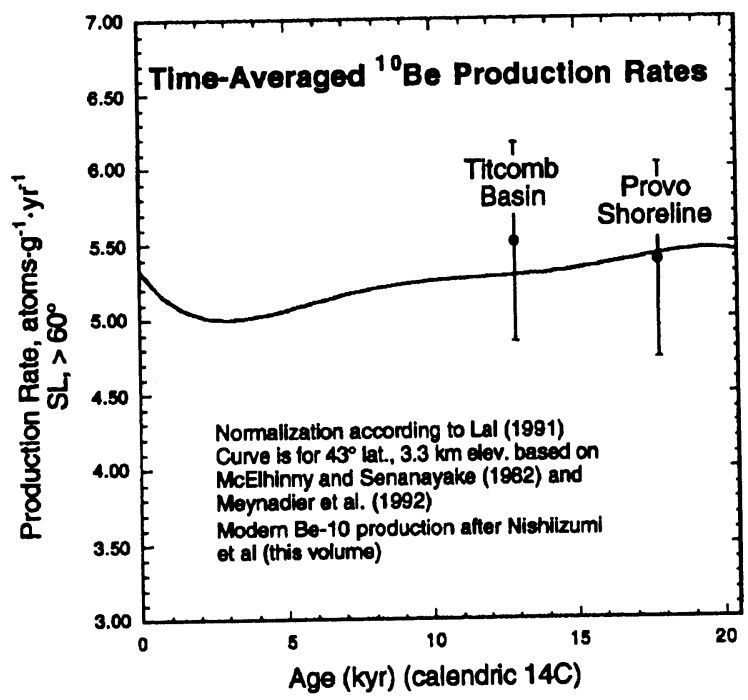

Preliminary results based on ${ }^{10} \mathrm{Be}$ measurements of two samples collected from a Provo Lake wave cut shoreline $\left(1.5 \mathrm{~km}, 41^{\circ} \mathrm{N}\right)$ will also be presented. The results suggest the time-averaged ${ }^{10} \mathrm{Be}$ production rate for $14.4{ }^{14} \mathrm{C} \mathrm{kyr}$ (Oviatt, Currey and Sak 1992; $17.6 \mathrm{cal} \mathrm{kyr}$ ) of exposure at sea level $>60^{\circ}$ latitude is $5.4 \pm 0.6$ atoms $\cdot \mathrm{g}^{-1} \mathrm{yr}^{-1}$ (uncertainty assigned as above).

\section{ADDITIONAL REFERENCES}

Davis, P. T. 1994 Late-glacial moraines in American Cordillera of Younger Dryas age? Geological Society of America Abstracts with Programs 26: A510.

Oviatt, C. G., Currey, D. R. and Sak, D. 1992 Radiocarbon chronology of Lake Bonneville, Eastern Great Basin, USA. Palaeography, Palaeoclimatology, Palaeoecology 99: 225-241

Zielinski, G. A. and Davis, P. T. 1987 Late Pleistocene age of the Type Temple Lake Moraine, Wind River Range, Wyoming, U.S.A. Géographie Physique et Quaternaire 41: 397-401.

\section{THE ${ }^{21}$ Ne PRODUCTION RATE IN A SI TARGET AT MOUNTAIN ALTITUDES}

\section{Th. GRAF, ${ }^{1}$ K. MARTI and R. C. WIENS ${ }^{2}$}

University of California, San Diego, La Jolla, California 92093-0317 USA

The isotopic signature of cosmic ray produced Ne was first measured in Antarctic rocks (Graf $e$ t al. 1991; Niedermann et al. 1993). Production rates of cosmogenic Ne were determined in quartz from glacially polished Sierra Nevada rocks which were exposed for only ca. $10^{4} \mathrm{yr}$ (Niedermann et al. 1994). However, past and present production rates of ${ }^{21} \mathrm{Ne}$ and other relevant cosmic ray produced nuclides are still poorly known. Temporal variations in the production rates can be studied by determinations of the products in well dated rocks and minerals thereof. The present production rates can 
be measured on exposed targets at mountain altitudes. We report first ${ }^{21} \mathrm{Ne}$ results obtained from a Si target exposed on Mt. Evans, Colorado.

We used an experimental melt (Corning Glass) substituting a small amount of $\mathrm{Li}$ for $\mathrm{Na}$. The glass $(2091 \mathrm{~g})$ was placed in a $13 \times 31 \mathrm{~cm}$ stainless steel cylinder. The stem was double valved to prevent leakage. To reduce self-shielding, the cylinder was designed to be only about half filled and lie on its side. The glass was degassed by heating numerous times above the softening temperature. Reaction of the glass with the stainless steel cylinder was apparent by glass analysis after the Ne study. The sample was exposed to cosmic rays for $c a .3 \mathrm{yr}$ on the summit of Mt. Evans, Colorado before it was transported to La Jolla for analysis.

Calibrations of the ${ }^{40} \mathrm{Ar}^{++}$and $\mathrm{CO}_{2}{ }^{++}$interferences on masses 20 and 22, respectively, revealed that the ratios of doubly to singly charged ${ }^{40} \mathrm{Ar}$ and $\mathrm{CO}_{2}$ ions are not constant. Our Ne analytical procedure monitors the peaks at masses $2,18,19,20,21,22,40,42$, and 44 . The ratios ${ }^{40} \mathrm{Ar}^{++} / 40 \mathrm{Ar}^{+}$and $\mathrm{CO}_{2}{ }^{++} / \mathrm{CO}_{2}{ }^{+}$, respectively, are calculated according to Graf et al. (1994) and the appropriate calibrations. The resulting interference corrections are subtracted individually for each cycle. We also need to calibrate the Ne sensitivity of the instrument as changes in the charge states and charge density in the ion source affect concentration measurements.

A significant fraction of the cosmic-ray produced $\mathrm{Ne}$ (36\%) was in the gas phase of the cylinder. $\mathrm{Ne}$ was then extracted in 3 steps at increasing temperatures and a re-extraction step at $950^{\circ} \mathrm{C}$ was added. Trapped Ne in all steps was fractionated up to $2 \%$ per amu, an effect that is presumably due to the extensive degassing prior to exposure. The total excess ${ }^{21} \mathrm{Ne}$ observed in the glass corresponds to 1500 atoms $\mathrm{g}^{-1}\left(\mathrm{SiO}_{2}\right)$ and we calculate a production rate $\mathrm{P}_{21}\left(\mathrm{SiO}_{2}\right)=410 \pm 60$ atoms a-1 $\mathrm{g}^{-1}\left(\mathrm{SiO}_{2}\right)$ at Mt. Evans $(4250 \mathrm{~m})$ altitude. The uncertainty includes current uncertainties in the $\mathrm{Ne}$ sensitivity and in mass discrimination which were added quadratically. The procedure of Lal (1991) is used to calculate the production at sea level, and $\mathrm{P}_{21}\left(\mathrm{SiO}_{2}\right)=19.3$ atoms a ${ }^{-1} \mathrm{~g}^{-1}\left(\mathrm{SiO}_{2}\right)$ for latitudes $>60^{\circ}$ is obtained. No corrections have yet been applied for self-shielding and for flux variations during the solar cycle (the exposure occurred during maximum solar activity). This value may be compared to a production rate $\mathrm{P}_{21}=21$ atoms $\mathrm{a}^{-1} \mathrm{~g}^{-1}$ (quartz) obtained by Niedermann et al. (1994) for Sierra Nevada quartz samples.

\footnotetext{
${ }^{1}$ Also at Institut für Isotopengeologie und Mineralische Rohstoffe, ETH Zürich, CH-8092 Zürich, Switzerland 2Present address: Division of Geological and Planetary Science, California Institute of Technology, Pasadena, California
91125 USA
} 


\section{RECENT AND PLANNED RESEARCH IN COSMOGENIC ISOTOPES AT GNS}

\section{IAN J. GRAHAM}

Institute of Geological and Nuclear Sciences, Ltd., Lower Hutt, New Zealand

The AMS laboratory at GNS was set up some ten years ago and has established an international reputation in ${ }^{14} \mathrm{C}$ analysis directed mainly towards archaeometry and atmospheric studies. A recently obtained calibration curve has provided a more secure basis for radiocarbon measurement. Tree rings from a section of native Matai covering the period $\mathrm{AD} 1335$ to 1745 have been dated and used to generate a ${ }^{14} \mathrm{C}$ calibration for Southern Hemisphere wood. Comparison of this curve with calibration data for Northern Hemisphere woods shows no systematic difference.

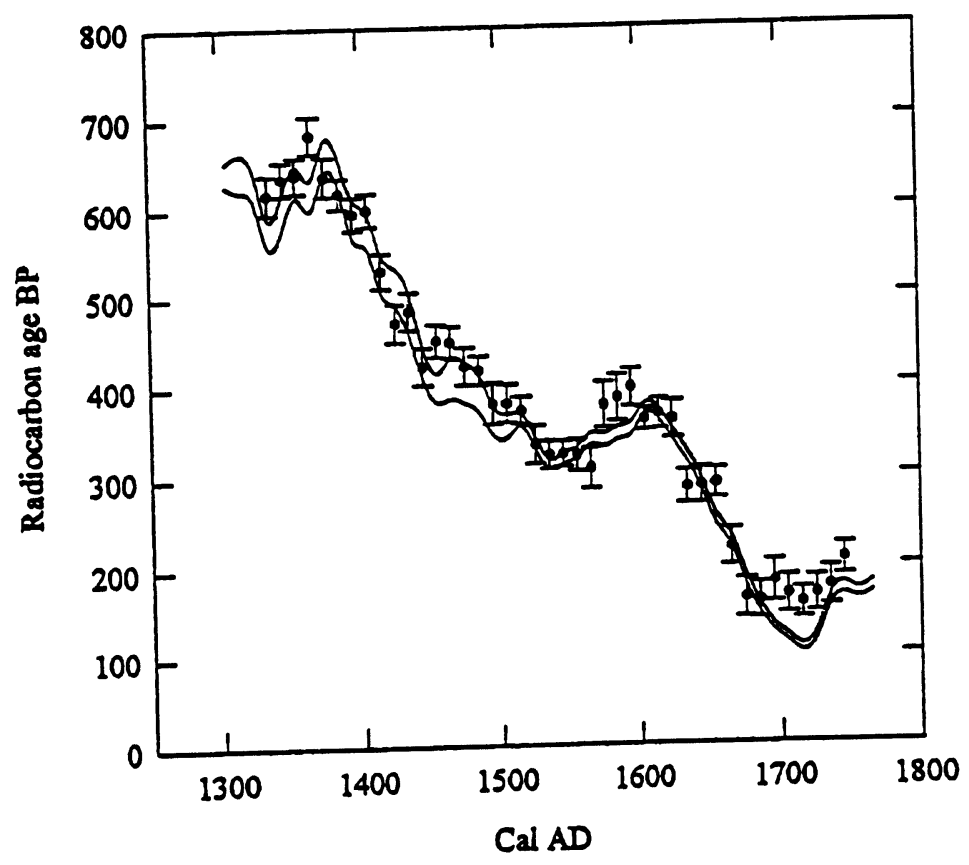

Research into other cosmogenic isotopes $\left({ }^{10} \mathrm{Be},{ }^{26} \mathrm{Al}\right.$ and $\left.{ }^{36} \mathrm{Cl}\right)$ at $\mathrm{GNS}$ is still in its infancy. Analysis of ${ }^{10} \mathrm{Be}$ in marine sediments, loess and Antarctic soils has yielded some interesting but inconclusive results. Planned research for 1996 involves direct measurement of ${ }^{10} \mathrm{Be}$ fluxes and in-situ production rates across a wide range of Southern Hemisphere geomagnetic latitudes $\left(3^{\circ} \mathrm{S}\right.$ to $\left.79^{\circ} \mathrm{S}\right)$. On-site measurement of neutron and/or muon flux is also planned. Sampling sites have been investigated and some preliminary rain collections made and measured. 


\section{DEPTH PROFILES OF COSMOGENIC NUCLIDES AND ACCELERATOR SIMULATION EXPERIMENTS WITH STOPPED NEGATIVE MUONS AND FAST
MUONS}

\section{B. HEISINGER, ${ }^{1}$ M. NIEDERMAYER, ${ }^{1}$ S. NEUMAIER,${ }^{1}$ F. J. HARTMANN,${ }^{1}$ G. KORSCHINEK, ${ }^{1}$ E. NOLTE, ${ }^{1}$ G. MORTEANI, ${ }^{1}$ C. PETITJEAN, ${ }^{2}$ P. KUBIK, ${ }^{2,3}$ A. SYNAL ${ }^{3}$ and S. IVY-OCHS ${ }^{3}$}

In-situ production of cosmogenic nuclides is important for the determination of background events in all low-level detection experiments, e.g., cryogenic dark matter detectors or geochemical experiments such as the geochemical solar neutrino experiment ${ }^{205} \mathrm{Tl}\left(v_{\mathrm{e}}, \mathrm{e}^{-}\right)^{205} \mathrm{~Pb}$ (Neumaier, Nolte and Morinaga 1991), and in many geophysical applications such as the determination of erosion rates.

The in-situ production of radionuclides has been calculated as the function of the depth $z$, taking into account spallation reactions, reactions with captured negative muons, reactions with fast muons and background reactions. The production rate due to $\mu^{-}$capture can be expressed by $P_{\mu-}(z)=I_{\mu-}(z) \cdot f_{C}$ $\cdot f_{D} \cdot f^{*}$ with the rate of stopped negative muons $I_{\mu-}(z)$, the chemical compound factor $f_{C}$, the probability of nuclear capture $f_{D}$ and the probability $f^{*}$ of the reaction channel after nuclear $\mu^{-}$capture to
the investigated nuclide or isomeric state.

The production due to fast muons is given by $\mathrm{P}_{\mu \text {,fast }}(\mathrm{z})=\Phi_{\mu \text {,fast }} \cdot \sigma$ with the flux of fast muons $\Phi_{\mu \text {,fast }}$. The energy-dependent cross section $\sigma$ is given by $\sigma=\sigma_{0} \cdot E_{\text {mean }} .7$ according to the Wolfendale rule with the mean muon energy $E_{\text {mean }}$ in $\mathrm{GeV}$ at the depth considered.

These contributions due to $\mu^{-}$capture and fast muons were studied by accelerator simulation experiments at PSI, Villigen, with slow negative muons and at CERN with $190 \mathrm{GeV}$ muons. The following probabilities $\mathrm{f}^{*}$ of particle emission channels after $\mu^{-}$capture have been measured in addition to earlier measurements (Dockhorn et al. 1991, Strack et al. 1994): $\mathrm{f}^{*}=(5.2 \pm 0.6) \cdot 10^{-3}$ for $\mathrm{O}\left(\mu^{-}\right.$, $\left.v_{\mu} \alpha \mathrm{pxn}\right)^{10} \mathrm{Be}[\mathrm{x}=1-3]$, and $\mathrm{f}^{*}=(1.4 \pm 0.4) \cdot 10^{-3}$ for $\mathrm{S}\left(\mu^{-}, v_{\mu} \alpha \mathrm{xn}\right)^{26} \mathrm{Al}[\mathrm{x}=2-4,6]$. From the result of the oxygen irradiation and the earlier result obtained for ${ }^{26} \mathrm{Al}$ from the irradiation of silicon, the production ratio of ${ }^{26} \mathrm{Al}$ to ${ }^{10} \mathrm{Be}$ after $\mu^{-}$capture in quartz has been deduced to be $\mathrm{P}\left({ }^{26} \mathrm{Al}\right) / \mathrm{P}\left({ }^{10} \mathrm{Be}\right)=$ $7.3 \pm 1.2$ (Heisinger et al.). For the determination of the fast muon cross section $\sigma_{0}$ of ${ }^{10} \mathrm{Be}$ (in $\mathrm{O}$ ), ${ }^{14} \mathrm{C}$ (in $\mathrm{O}$ ), ${ }^{26} \mathrm{Al}$ (in $\mathrm{Si}, \mathrm{S}$ and $\mathrm{Al}$ ), ${ }^{36} \mathrm{Cl}$ (in $\mathrm{Ca}$ ), ${ }^{53} \mathrm{Mn}$ (in $\mathrm{Fe}$ ) and ${ }^{205} \mathrm{~Pb}$ (in $\mathrm{Tl}$ ) several targets have been irradiated at CERN. This work is still in progress.

In addition, natural depth profiles of ${ }^{10} \mathrm{Be}$ and ${ }^{26} \mathrm{Al}$ in quartz have been measured in Northern Bavaria up to depths of $250 \mathrm{~m}$ and have been compared, taking erosion into account, with calculated profiles. From this comparison, the erosion rate for the last million years has been determined to be ca. $5 \mu \mathrm{m} \mathrm{yr}^{-1}$ (Heisinger et al.).

\section{REFERENCES} Heisinger, B., Niedermayer, M., Hartmann, F. J., Korschinek, G., Neumaier, S., Nolte, E., Morteani, G., Petitjean, C., Kubik,
P., Synal, A. and Ivy-Ochs, S. to be published.

Neumaier, S., Nolte, E. and Morinaga, H. 1991 Feasibility studies of the geochemical solar neutrino experiment ${ }^{205} \mathrm{Tl}\left(v_{\mathrm{e}}, \mathrm{e}^{-}\right)$
${ }^{205} \mathrm{~Pb}$. Zeitschrift für PhysikA 340: 415-418.

${ }^{1}$ Technical University of Münich, D-85747 Garching, Germany

${ }^{2}$ Paul Scherrer Institute, CH-5232 Villigen PSI, Switzerland

${ }^{3}$ ETH-Hönggerberg, CH-8093 Zürich, Switzerland 


\section{NEUTRON-INDUCED PRODUCTION CROSS SECTIONS FOR LONG-LIVED NUCLIDES AND RARE GASSES: SOME EXPERIMENTAL DATA}

\section{MINEO IMAMURA}

Institute for Nuclear Study, The University of Tokyo 3-2-1, Midori-cho, Tanashi, Tokyo 188 Japan

We present data on neutron-induced nuclear cross sections for the production of long-lived radionuclides of ${ }^{3} \mathrm{H},{ }^{7,10} \mathrm{Be},{ }^{14} \mathrm{C},{ }^{26} \mathrm{Al}$ and ${ }^{36} \mathrm{Cl}$ and rare gases ${ }^{21,22} \mathrm{Ne}$, which have been measured by our group in the last several years, using semi-monoenergetic neutrons from the ${ }^{9} \mathrm{Be}(\mathrm{p}, \mathrm{n})$ and $/$ or ${ }^{7} \mathrm{Li}(\mathrm{p}, \mathrm{n})$ reactions.

Cosmogenic nuclide production rates depend on chemical composition of the sample material and on particle fluxes of cosmic ray secondaries. Neutrons with energies up to a few hundreds $\mathrm{MeV}$ are the major contributing particles in terrestrial environments. Since the neutron energy spectrum depends considerably on the chemical composition of surrounding materials, knowledge of cross sections is indispensable for understanding the production rates in various terrestrial environments. Production cross sections are determined in most cases by counting the number of atoms produced from the known number of target atoms by irradiating with a known particle fluence. Because of the absence of an appropriate monoenergetic source, there have been very few experimental data on neutron-induced cross sections for energies above $20 \mathrm{MeV}$. Above $20 \mathrm{MeV}$, the most practical way is to use semi-monoenergetic neutrons from secondary emission through the ${ }^{9} \mathrm{Be}(\mathrm{p}, \mathrm{n})$ and ${ }^{7} \mathrm{Li}(\mathrm{p}, \mathrm{n})$ reactions.

We have two facilities available for semi-monoenergetic neutron irradiation: the SF cyclotron facility at the Institute for Nuclear Study (INS), University of Tokyo for $10-38 \mathrm{MeV}$, and the AVF cyclotron facility at the Japanese Atomic Energy Research Institute (JAERI) in Takasaki for $40-90 \mathrm{MeV}$ (Nakamura et al. 1994). In addition, we have used the Van de Graaff accelerator at the Fast Neutron Laboratory (FNL) at Tohuku University for $<1-16 \mathrm{MeV}$ monoenergetic neutrons. Because of the limited machine time, many of the cross section studies are still underway. In the workshop I will present the data (including the published ones) on production of ${ }^{3} \mathrm{H}$ from oxygen $(<40 \mathrm{MeV}),{ }^{7,10} \mathrm{Be}$ from $\mathrm{C}, \mathrm{N}$ and $\mathrm{O}(<70 \mathrm{MeV}),{ }^{26} \mathrm{Al}$ from $\mathrm{Al}$ and $\mathrm{Si}(<40 \mathrm{MeV}),{ }^{21,22} \mathrm{Ne}$ from $\mathrm{Mg}$ and $\mathrm{Al}(<40 \mathrm{MeV})$.

\section{REFERENCE}

Nakamura, T., Soewarsono, T. S., Uno, Y., Nakao, N., Uwamino, Y., Imamura, M., Ishikawa, T., Tanaka, Sh., Nakashima, H., Tanaka, S., Baba, M. and Iwaskai, T. 1994 In Proceedings of the 8th International Conference on Radiation Shielding. American Nuclear Society, La Grande Park: 264-271.

\section{A COMPARISON OF ${ }^{10} \mathrm{Be},{ }^{26} \mathrm{Al},{ }^{36} \mathrm{Cl}$ IN BOULDERS FROM A YOUNGER DRYAS MORAINE, JULIER PASS, GRAUBÜNDEN, SWITZERLAND}

SUSAN IVY-OCHS, ${ }^{1}$ CHRISTLAN SCHLÜCHTER, ${ }^{2}$ PETER KUBIK, ${ }^{3}$ HANS-ARNO SYNAL ${ }^{3}$ and
JÜRG BEER ${ }^{4}$

${ }^{10} \mathrm{Be},{ }^{26} \mathrm{Al}$, and ${ }^{36} \mathrm{Cl}$ measured in six boulders from an Egesen moraine complex at Julier Pass, Switzerland, gave a mean age of $c a$. 11,000 yr. Radiocarbon dating, geomorphologic evidence and regional correlation constrain Egesen moraines to have been formed as Alpine glaciers advanced during the Younger Dryas (YD) cold event $\left(11,000\right.$ to $10,000{ }^{14} \mathrm{C}$ yr ago). Corrections for thickness of sample and topographic shielding have been made, but snow and erosion corrections have not. 
With the latitude and altitude corrections stated in Lal (1991) as a basis, production rates for the three isotopes can then be examined. Overall, the agreement of the surface exposure ages from different isotopes in single boulders, between all six boulders and with the known age of the YD is very good. This leaves little room for significant changes in production rates over the last $c a .12,000 \mathrm{yr}$ and indicates that present production rates (Nishiizumi et al. 1989; Phillips et al. 1996) are not that far off.

\footnotetext{
${ }^{1}$ Institut für Teilchenphysik and Ingenieurgeologie, ETH Hönggerberg, CH 8093 Zürich, Switzerland

${ }^{2}$ Geologisches Institut, Universität Bern, CH 3012 Bern, Switzerland

${ }^{3}$ PSI c/o Institut für Teilchenphysik, ETH Hönggerberg, CH 8093 Zürich, Switzerland

${ }^{4}$ EAWAG, CH-8600 Dübendorf, Switzerland
}

\section{PRODUCTION OF ${ }^{14} \mathrm{C}$ AND ${ }^{10}$ Be IN THE ATMOSPHERE AND ON THE EARTH'S
SURFACE}

\section{A. J. T. JULL, ${ }^{1,2}$ L. R. MCHARGUE, ${ }^{1,2}$ N. A. LIFTON,,$^{1,2}$ W. M. PHILLIPS ${ }^{1,3}$ and J. QUADE}

In recent years, there has been growing interest in the production of cosmogenic nuclides in rock surfaces as well as in the atmosphere, because of possible applications to a variety of fields. Geophysical and temporal variations in the production rates of cosmogenic nuclides must be understood in order to be useful for such diverse applications as estimating the exposure ages of a geomorphic surface based on in-situ-produced cosmogenic nuclides and calibration of ${ }^{14} \mathrm{C}$ ages.

Jull et al. (1988) reported the first measurements of cosmogenic ${ }^{14} \mathrm{C}$ in terrestrial rocks based an extension of earlier work on meteorites (Jull et al. 1989). Measurable levels of in-situ-produced cosmogenic ${ }^{14} \mathrm{C}$ have been found in rocks collected from 3300 to $5452 \mathrm{~m}$ from North and Central America and Hawaii (Jull et al. 1988, 1992, 1994; Donahue, Jull and Toolin 1990). These measurements allowed us to estimate differences in sea-level production rate on the basis of latitude. Temporal changes in atmospheric and in-situ ${ }^{14} \mathrm{C}$ production rates are also significant. Tree-ring data suggest that substantial variations in the production rate of ${ }^{14} \mathrm{C}$ in the atmosphere occur (Damon and Sonett 1991). We know that the production 10,000 yr ago was of the order of $10 \%$ higher than today. Bard et al. (1990) argue for larger variations of up to $40 \%$ in the Late Pleistocene, based on comparisons of ${ }^{14} \mathrm{C}$ ages with $\mathrm{U}$-Th ages of corals. Long-term variations in the tree-ring ${ }^{14} \mathrm{C}$ are probably due to geomagnetic variations, although short-term variations are thought to be solar (Damon and Sonett 1991). Bard et al. (1990) argue that same geomagnetic influences can explain the larger ${ }^{14} \mathrm{C}$ effects seen in late Pleistocene coral results. Edwards et al. (1993) studied ${ }^{14} \mathrm{C}$ in Late Pleistocene corals and found larger effects than can be ascribed to geomagnetic effects. Oceanic effects must have a strong, if not dominant, effect on atmospheric ${ }^{14} \mathrm{C}$ variations.

For in-situ produced isotopes, however, geomagnetic effects are expected to predominate. Estimating geomorphic surface exposure ages or erosion rates using in-situ cosmogenic nuclide measurements requires us to know the average production rate over the exposure time of the surface. The record of ${ }^{10} \mathrm{Be}$ produced in the atmosphere, observed in deep-sea sediments and ice, gives us a possible way of estimating these integral variations. Integration of ${ }^{10} \mathrm{Be}$ in a marine sediments suggests that the effect of "spikes" at 30, 43 and $60 \mathrm{Ka}$ due to cosmic-ray fluctuations possibly due to supernova or other transient phenomena (McHargue et al. 1995) will not have much effect on ${ }^{14} \mathrm{C}$. The total effect on in-situ-produced ${ }^{14} \mathrm{C}$ is $<10 \%$. Similarly, such "spikes" cannot explain the deviations of ${ }^{14} \mathrm{C}$ and U-Th observed by Bard et al. (1990), which are probably a combination of oceanic and 
geomagnetic influences. However, transient changes in the cosmic-ray flux would likely have greater effects on longer-lived nuclides.

TABLE 1. Production Rates of In-Situ-Produced ${ }^{14} \mathrm{C}$ as a Function of Latitude

\begin{tabular}{lccl}
\hline Sample & $\begin{array}{c}\text { Geomagnetic } \\
\text { latitude }\end{array}$ & $\begin{array}{c}\text { sea level } \\
\left({ }^{14} \mathrm{C} / \mathrm{g} / \mathrm{yr}\right)\end{array}$ & Reference \\
\hline Mt. Massive, Colorado & $49^{\circ} \mathrm{N}$ & $21 \pm 2$ & $\begin{array}{l}\text { Jull } \text { et al. }(1988) ; \\
\text { Donahue, Jull and Toolin (1990) }\end{array}$ \\
Tabernacle Hill, Utah & $49^{\circ} \mathrm{N}$ & $20 \pm 2$ & Jull et al. (1992) \\
La Malinche, Mexico & $28^{\circ} \mathrm{N}$ & $16 \pm 2$ & Jull et al. $(1988)$ \\
Popocatepetl, Mexico & $28^{\circ} \mathrm{N}$ & $12 \pm 2$ & Jull et al. $(1988)$ \\
Mauna Loa, Hawaii & $18^{\circ} \mathrm{N}$ & $15 \pm 2$ & Donahue, Jull and Toolin (1990) \\
\hline
\end{tabular}

\section{ADDITIONAL REFERENCES}

Damon, P. E. and Sonett, C. P. 1991 In C. P. Sonett et al., eds., The Sun in Time. Tucson, University of Arizona Press: 360-388. Donahue, D. J., Jull, A. J. T. and Toolin, L. J. 1990 Nuclear Instruments \& Methods B52: 224-228.

Edwards, R. L., Beck, J. W., Burr, G. S., Donahue, D. J., Chappell, J. M. A., Bloom, A. L., Druffel, E. R. M. and Taylor, F. W. 1993 Science 260: 962-968.

Jull, A. J. T., Donahue, D. J. and Linick, T. W. 1989 Geochimica Cosmochimica Acta 53: 1295-1300.

McHargue, L., Damon, P. E. and Donahue, D. J. 1995 Enhanced cosmic-ray production of ${ }^{10} \mathrm{Be}$ coincident with the Mono Lake and Laschamp geomagnetic excursions. Geophysical Research Letters 22: 659-662.

${ }^{1}$ NSF-Arizona AMS Facility, The University of Arizona, Tucson, Arizona 85721 USA

${ }^{2}$ Department of Geosciences, The University of Arizona, Tucson, Arizona 85721 USA

${ }^{3}$ Los Alamos National Laboratory, Los Alamos, New Mexico 87545 USA

\section{TERRESTRIAL FACTORS THAT INFLUENCE PRODUCTION RATES}

\section{J. KLEIN}

Department of Physics, University of Pennsylvania, Philadelphia, Pennsylvania 19104-6396 USA

and

\section{J. GOSSE}

EES-1 Los Alamos National Laboratory, Los Alamos, New Mexico 87545 USA

Production rates of cosmogenic nuclides on Earth undergo temporal variations. These variations are caused by extraterrestrial factors that are expected to affect production rates uniformly everywhere on Earth and by terrestrial factors that cause changes in production rates that vary with location. Accurate age determinations using techniques that rely on the accumulation of cosmogenic nuclides require a knowledge of production rates for the periods during which the samples were exposed. Measurements are now made with sufficient precision that the uncertainty of an age determination is often set by limitations in our knowledge of time-varying production rates. Knowing what causes the changes in production rates is important when transferring production rates measured in one location to other places on earth. Additionally, an appreciation of the possible causes of variations in production rates should inform the selection of locations chosen for calibrations. 
For example, the terrestrial factor that has been blithely assumed to have the greatest effect on production rates is the strength of the Earth's magnetic field. However, the figure on the following page shows that at latitudes above $20^{\circ}$ an equally important factor may be the position of the magnetic pole relative to the geographic pole. The distinction between field strength and pole position is an important one, not only because different latitudinal profiles must be used to calculate production rates from known changes in field strength and pole position, but also because additional data are needed to determine the position of the pole at the site used for calibration. These additional data may be magnetic declination and inclination measurements at the sampling location, or measurements of relative production rates at positions of similar age and latitude but at different longitude. A recognition of the importance of pole position changes the approach one uses to establish the calibration data.

Other factors that will be addressed include local changes in atmospheric density resulting from sealevel lowering and terrestrial-ice buildup during periods of glaciation and long-term effects of isostatic compensation.

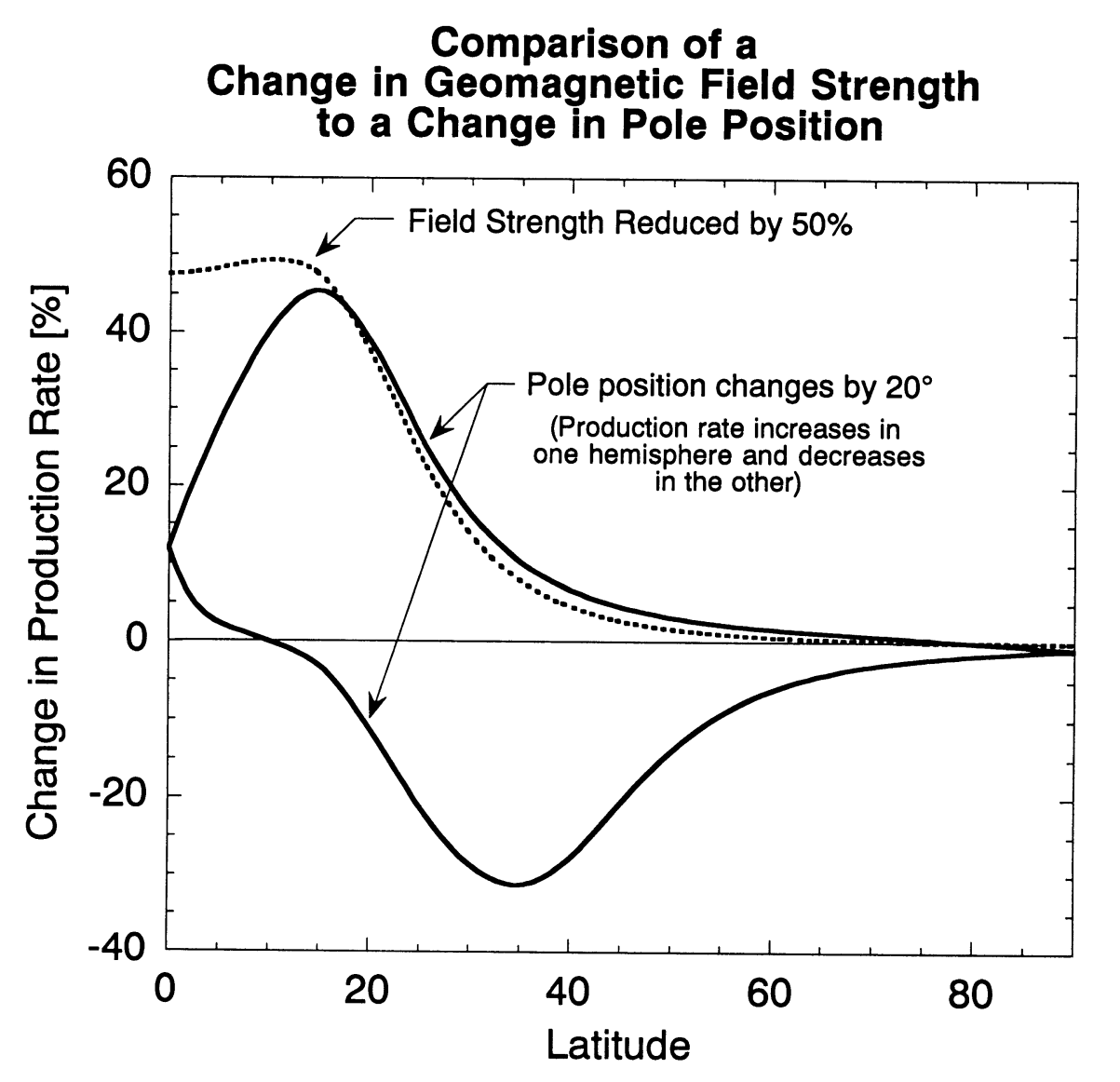




\title{
MONTE CARLO SIMULATION OF IN-SITU-PRODUCED COSMOGENIC NUCLIDES
}

\author{
JOZEF MASARIK
}

Max-Planck-Institut für Chemie, Abteilung Kosmochemie, Postfach 3060, D-55020 Mainz, Germany

and ROBERT C. REEDY

Astrophysics and Radiation Measurements Group, Mail Stop D436, Los Alamos National Laboratory, Los Alamos, New Mexico 87545 USA

Cosmogenic nuclides produced in situ in terrestrial surface samples provide an important tool for dating and determining erosional histories of landforms. Reliable interpretation of the measured nuclide contents requires a good understanding of fundamentals of nuclide production mechanisms. We present a pure physical model (Masarik and Reedy 1995) for the simulation of the relevant processes enabling an investigation of nuclide production dependence on depth, composition, atmospheric thickness, and geomagnetic field intensity.

In our simulation model (Masarik and Reedy 1994, 1995), the spectra of particles inducing reactions that produce cosmogenic nuclides are calculated by Monte Carlo numerical simulations using the LAHET Code System (LCS) and the GEANT code. Having calculated neutron fluxes with these codes, the production rates of nuclides are determined by integrating over energy the product of these fluxes with experimental and evaluated cross sections for the reactions producing each nuclide. Technical details of the LCS model and our approach are described in Masarik and Reedy (1995). This approach is similar to that often used and well tested by us for cosmogenic-nuclide production rates in lunar samples and meteorites (e.g., Masarik and Reedy 1994).

We simulated the irradiation of Earth with an isotropic GCR particle flux with an energy distribution corresponding to the GCR primary particle flux averaged over a solar cycle. The Earth was modeled as a sphere with a $6378-\mathrm{km}$ radius and an average crustal elemental composition. The model atmosphere has a $1030-\mathrm{g} / \mathrm{cm}^{2}$ thickness and its standard composition, density, and temperature profiles (Masarik and Reedy 1995). Running $10^{7}$ primary particles, we obtained surface neutron fluxes with statistical errors of $\sim 8 \%$. Although we calculated muon fluxes, their contribution to the production rate was not considered by us because of the lack of the data needed to convert muon fluxes to production rates.

Except for $\mathrm{H}$ and $\mathrm{Fe}$, most changes in the surface composition or the addition of other elements to the assumed composition have very little effect on the calculated fluxes (Masarik and Reedy 1994). Therefore elemental production rates valid for many types of rocks can be obtained from these fluxes. The total production rates (in atoms per gram-element per year) only by neutrons and for high latitudes and sea level are given by

$$
\begin{aligned}
& \mathrm{P}\left({ }^{10} \mathrm{Be}\right)=10.87[\mathrm{O}]+0.52[\mathrm{Mg}]+0.39[\mathrm{Si}]+0.45[\mathrm{Al}]+0.16[\mathrm{Fe}] \\
& \mathrm{P}\left({ }^{14} \mathrm{C}\right)=31.3[\mathrm{O}]+5.3[\mathrm{Mg}]+4.2[\mathrm{Al}]+4.3[\mathrm{Si}]+1.2[\mathrm{Fe}] \\
& \mathrm{P}\left({ }^{26} \mathrm{Al}\right)=225[\mathrm{Al}]+77[\mathrm{Si}]+0.15[\mathrm{Fe}] \\
& \mathrm{P}\left({ }^{36} \mathrm{Cl}\right)=129[\mathrm{~K}]+65[\mathrm{Ca}]+16[\mathrm{Ti}]+0.9[\mathrm{Fe}] \\
& \mathrm{P}\left({ }^{21} \mathrm{Ne}\right)=98[\mathrm{Na}]+131[\mathrm{Mg}]+65[\mathrm{Al}]+39[\mathrm{Si}]+4[\mathrm{Ca}]+0.20[\mathrm{Fe}] \\
& \mathrm{P}\left({ }^{3} \mathrm{He}\right)=135[\mathrm{O}]+116[\mathrm{Mg}]+107[\mathrm{Al}]+111[\mathrm{Si}]+61[\mathrm{Ca}]+40[\mathrm{Fe}]
\end{aligned}
$$


in which the target-element concentrations, such as [O], are in weight fractions. The calculated rates for most minor target elements are not well tested and could have considerable uncertainties. Latitude-altitude production rates for all above listed nuclides were also calculated. The results of our model calculations are in good agreement with most recent measurements (Masarik and Reedy 1995).

\section{PRODUCTION RATE OF ${ }^{10}$ Be AND ${ }^{26}$ Al ON THE SURFACE OF THE EARTH AND UNDERGROUND}

\section{KUNIHIKO NISHIIZUMI}

Space Sciences Laboratory, University of California, Berkeley, California 94720-7450 USA

To apply in-situ produced cosmogenic nuclides to the study of Earth surface processes, production rates at the surface of the Earth and the attenuation length of the production underground must be known. I review present understanding of ${ }^{10} \mathrm{Be}$ and ${ }^{26} \mathrm{Al}$ production rates from quartz, based on different methods and covering various time scales. Each method has its merits and limitations that must be understood in order to assess the reliability of the production rates.

A. Geological Methods: Geological methods require that the exposure conditions of the samples studied be constant and that they be well known. Production rates are averages over changes of the Earth's magnetic field and of the primary cosmic ray flux.

1. Concentration of ${ }^{10} \mathrm{Be}$ and ${ }^{26} \mathrm{Al}$ in quartz from glacially polished rocks (Nishiizumi et al. 1989): Since samples are uneroded, nuclides with various half-lives can be compared in the same sample (Neidermann et al. 1994). Uncertainties in the exposure age (glaciation age) and in the geomagnetic latitude correction must be considered.

2. Concentration of ${ }^{10} \mathrm{Be}$ and ${ }^{26} \mathrm{Al}$ in saturated rocks (Nishiizumi et al. 1991; Brown et al. 1991): The high concentrations of cosmogenic ${ }^{21} \mathrm{Ne}$ (Hudson et al. 1991) insure that the activities of ${ }^{10} \mathrm{Be}$ and ${ }^{26} \mathrm{Al}$ in certain Antarctic rocks are saturated (decay rate is the same as the production rate). Effects of changing geomagnetic intensity can be ignored for these high latitude samples. Because of the possible influence of erosion, the production rate estimates are lower limits. In addition, there is an uncertainty arising from uplift of the samples during the million year exposure period.

B. Theoretical Calculation (ex. Masarik and Reedy 1995): The accuracy of calculated production rates depends on the model and on knowledge of excitation functions. The increasing availability of laboratory data (Imamura et al. 1990; Reedy et al. 1994) improves the reliability of the results. The method can be applied to samples of various size and shape.

C. Direct Measurements of ${ }^{10}$ Be Production in a Water Target (Nishiizumi et al. 1995): Exposure conditions are unambiguous but the exposure age is very short compared to the geological time scale. There is an uncertainty arising from secular variations of the Earth's magnetic field and of the primary cosmic ray flux. 
TABLE 1. Comparison of ${ }^{10} \mathrm{Be}$ Production Rates (atom $/ \mathrm{gSiO}_{2} / \mathrm{yr}$ at sea level, $>50^{\circ}$ )

\begin{tabular}{|c|c|c|c|}
\hline Method & Time scale & $\begin{array}{l}{ }^{10} \mathrm{Be} \text { production rate } \\
\text { (atom } / \mathrm{gSiO}_{2} / \mathrm{yr} \text { ) }\end{array}$ & Reference \\
\hline Water targets & 4 solar cycles & $5.32 \pm 0.27$ & Nishiizumi et al. 1995 \\
\hline $\begin{array}{l}\text { Water targets (after } \\
\text { geomagnetic correction) }\end{array}$ & $11,000 \mathrm{yr}$ & $6.1 \pm 0.3$ & Nishiizumi et al. 1995 \\
\hline $\begin{array}{l}\text { Glacially polished rocks } \\
\text { at Sierra Nevada }\end{array}$ & $11,000 \mathrm{yr}$ & 6.03 & Nishiizumi et al. 1989 \\
\hline Antarctic Rocks & $\geq 4 \mathrm{My}$ & 6.13 & Nishiizumi et al. 1991 \\
\hline Antarctic Rocks & $\leq 2.5 \mathrm{My}$ & 6.4 & Brown et al. 1991 \\
\hline Theoretical calculation & > several My & 5.97 & Masarik and Reedy 1995 \\
\hline
\end{tabular}

\section{REFERENCES}

Brown, E.,T. et al. 1991 Geochimica Cosmochimica Acta 55: 2269-2283.

Hudson, G. B. et al. 1991 Trans. American Geophysical Union 72(44): 575.

Imamura, M. et al. 1990 Nuclear Instruments and Methods B52, 595-600.

Niedermann, S. et al. 1994 Earth Planetary Science Letters 125: 341-355.

Masarik, J. and Reedy, R. C. 1995 Earth Planetary Science Letters, in press.

Nishiizumi, K. et al. 1989 Journal of Geophysical Research 94: 17907-17915. 1991 Earth Planetary Science Letters 104: 440-454.

1995 Journal of Geophysical Research submitted.

Reedy R. C. et al. 1994 Nuclear Instruments and Methods B92: 297-300.

\section{COSMIC-RAY NEUTRONS AT GROUND LEVEL: TEMPORAL AND GEODETIC VARIATIONS}

\section{KERAN O'BRIEN}

Department of Physics and Astronomy, Northern Arizona University, P.O. Box 6010, Flagstaff, Arizona 86011-6010 USA

Ground-level cosmic-ray neutrons are the major producer of near-surface cosmogenic isotopes. The inventory of a cosmogenic isotope at a particular location at a particular time depends on the past temporal variation of the neutron flux at that location. To obtain the sensitivity of terrestrial groundlevel neutron fluxes on time and space, ground-level fluxes have been calculated using LUIN94 (O'Brien 1995) as a function of geodetic coordinates, altitude, solar activity and magnetic field intensity. The geomagnetic field was treated in considerable detail, using the 1980 Epoch vertical cutoff calculations of Shea and Smart (1983), obtaining the non-vertical cutoffs by means of the approach of Rösler (personal communication) and Heinrich and Spill (1979). Solar modulation was treated in the heliocentric potential approximation. Results are presented graphically. The tabular data underlying these data or the codes used to generate them will be given to anyone interested.

\section{REFERENCES}

Heinrich, W. and Spill, A. 1979 Geomagnetic shielding of cosmic rays for different satellite orbits. Journal of Geophysical Research 84: 4401-4401.

O'Brien, K., Friedberg, W., Sauer, H. and Smart, D. (Plenary lecture) Atmospheric cosmic rays and solar energetic particles at aircraft altitudes. International Symposium on the Natural Radiation Environment, Montréal, Canada, 9 June 1995.

Shea, D. and Smart, F. 1983 A world grid of calculated cosmic ray vertical cutoff rigidities for 1980.0, 18th International Cosmic Ray Conference, Conference Papers 3: 415. 


\section{MORE REVEALING HISTORIES OF EXPOSURE: THE RAT URINE STORY}

\section{FRED M. PHILLIPS, MITCHELL PLUMMER and MONTGOMERY FLINSCH}

Department of Earth and Environmental Science, New Mexico Tech, Socorro, New Mexico 87801 USA

Accurate surface exposure dating using cosmogenic nuclides will require correcting for the effects of secular variations in the production rates of cosmogenic nuclides, presumably mostly due to fluctuations in the intensity of the geomagnetic field. The two main sources of data about these variations are paleomagnetic intensity reconstructions (mostly from sediment cores) and documented discrepancies between ${ }^{14} \mathrm{C}$ ages and independent ages. Unfortunately, environmental conditions during deposition can affect the accuracy of paleomagnetic intensity reconstructions, and their reliability is difficult to assess. Variations in cosmogenic production can be back-calculated from the ${ }^{14} \mathrm{C}$ discrepancies, but the magnitude of these discrepancies is strongly affected by changes in oceanic circulation. We have measured ${ }^{36} \mathrm{Cl}$ in fossil packrat urine in order to provide an independent basis for reconstructing variations in cosmogenic nuclide production. The record of ${ }^{36} \mathrm{Cl}$ fluctuations thus obtained shares many features with the ${ }^{14} \mathrm{C}$ and paleomagnetic reconstructions, but indicates a larger and more abrupt decrease in cosmogenic production at the end of the last glacial period. 


\section{COMPARISON OF DATES FOR YOUNG BASALTS FROM THE ${ }^{40} \mathrm{Ar} /{ }^{39} \mathrm{Ar}$ AND COSMOGENIC HELIUM TECHNIQUES}

\section{J. POTHS, ${ }^{1}$ E. Y. ANTHONY, ${ }^{2}$ W. J. WILLIAMS, ${ }^{2}$ M. HEIZLER ${ }^{3}$ and W.C. MCINTOSH ${ }^{3}$}

We have ${ }^{3} \mathrm{He}$ surface exposure dates and ${ }^{40} \mathrm{Ar} /{ }^{39} \mathrm{Ar}$ dates for a number of lavas from three volcanic fields: Potrillo (New Mexico), Lathrop Wells (Nevada), and San Quintin (Baja California, Mexico). The dates span from $20 \mathrm{ka}$ to $150 \mathrm{ka}$. While agreement among the two types of dates is encouraging, it is not universal. Both types of dates have their associated assumptions that can bias the results: $\mathrm{He}$ dates for older lavas may be lower than the eruption age due to erosion, while ${ }^{40} \mathrm{Ar} /{ }^{39} \mathrm{Ar}$ dates at low radiogenic yields are sensitive to assumptions about the trapped component. A particularly encouraging approach is ${ }^{40} \mathrm{Ar} /{ }^{39} \mathrm{Ar}$ dating of sanidine separated from xenoliths. At Lathrop Wells, a subset of these xenoliths yields an upper limit for the age of the Q12 flow of $75( \pm 2) \mathrm{ka}$, slightly younger than the ${ }^{3} \mathrm{He}$ date $(85 \pm 5 \mathrm{ka})$. This observation, as well as the general comparison of $\mathrm{Ar}$ and ${ }^{3} \mathrm{He}$ dates (figure below), suggests that the integrated production rate for ${ }^{3} \mathrm{He}$ is slightly higher at $c a .80$ $\mathrm{ka}$, compared to that derived from Tabernacle Hill at $17 \mathrm{ka}$.

\section{Comparison of He and Ar Dates}

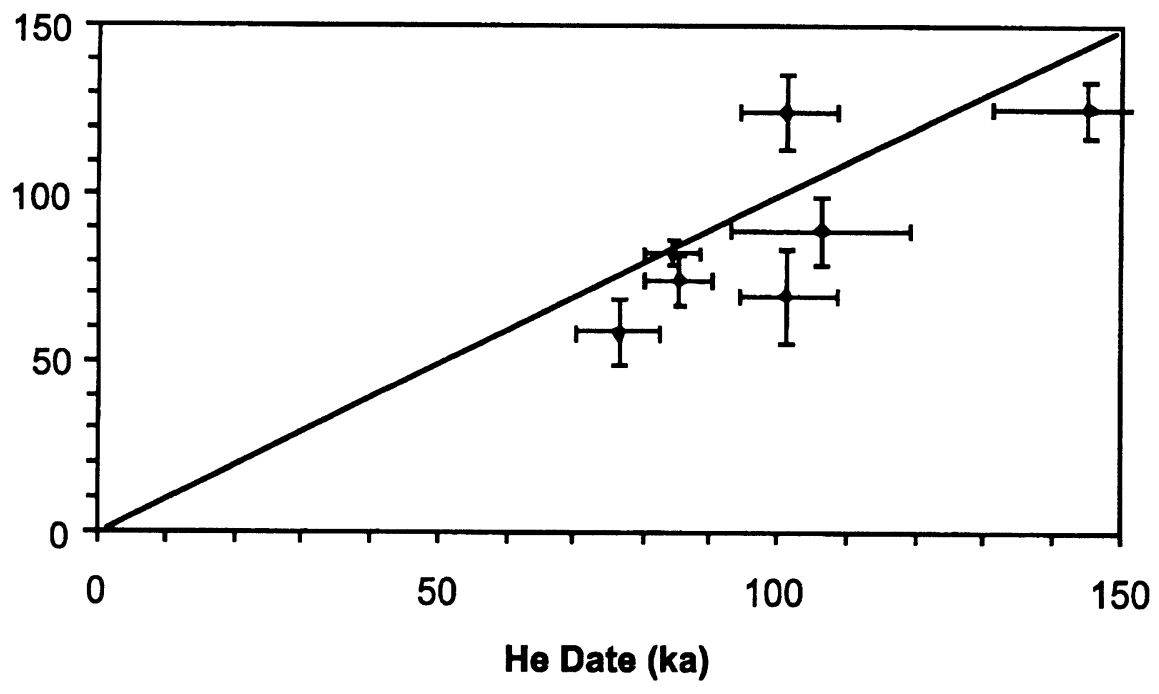

${ }^{1}$ CST-7, Los Alamos National Lab, Los Alamos, New Mexico 87545 USA

${ }^{2}$ Department of Geological Sciences, University of Texas at El Paso, El Paso, Texas 79968 USA

${ }^{3}$ New Mexico Bureau of Mines, Socorro, New Mexico 87801 USA 


\section{PRODUCTION SYSTEMATICS OF COSMOGENIC NUCLIDES IN THE EARTH}

\section{ROBERT C. REEDY}

Mail Stop D436, Los Alamos National Laboratory, Los Alamos, New Mexico 87545 USA

The high-energy $(\mathrm{GeV})$ particles in the galactic cosmic rays (GCR) produce nuclides deep in any object exposed to them. Cosmogenic nuclides have been well studied since the 1950s in meteorites and lunar samples. In extraterrestrial matter, several approaches have been used to determine cosmogenic-nuclide production systematics. The work being done for terrestrial cosmogenic nuclides (e.g., Reedy et al. 1994a) follows the approach used for extraterrestrial nuclides.

For extraterrestrial cosmogenic nuclides, initial studies used activities of radionuclides to infer production rates. (For a long, constant exposure to cosmic rays, a radionuclide's decay rate approaches equilibrium with its production rate.) Irradiations of thick targets at high-energy accelerators were done to experimentally simulate GCR irradiations in space and helped in understanding the nuclear processes involved. Accelerators were also used with thin targets to measure cross sections for making these cosmogenic nuclides. Several models were developed for predicting the systematics of the production of cosmogenic nuclides, mainly semi-empirical fits. Recently, numerical simulations based only on physics have been used to study nuclear reactions and allow us to examine the details of how GCR particles interact with matter (Masarik and Reedy, this issue).

The terrestrial case is more complicated because of the Earth's atmosphere and strong geomagnetic field. Most GCR particles interact in the Earth's atmosphere, making mainly ${ }^{14} \mathrm{C}$. The Earth's thick $\left(1033 \mathrm{~g} / \mathrm{cm}^{2}\right)$ atmosphere attenuates the flux of particles reaching the surface by several orders of magnitude. The large difference in the composition and density of the atmosphere compared to extraterrestrial matter makes it difficult to use data from extraterrestrial matter for nuclides made deep in the atmosphere. One major difference is that most pions made in dense extraterrestrial matter interact before they can decay, while most pions in the thin atmosphere decay to muons. These muons are weakly-interacting particles and can go much further than strong-interacting particles such as neutrons and pions. Below a few meters in the Earth's surface, muons are a major source of cosmogenic nuclides. Another complication is that the production rates of a nuclide in the Earth's surface can vary much with the sample's elevation and the location's geomagnetic latitude.

Most production rates of nuclides made in the Earth are now based on a few measurements made with natural samples. Generally, the production rate of a cosmogenic nuclide is converted from that determined at the location's elevation and geomagnetic latitude to the rate at sea level and a high geomagnetic latitude $\left(>60^{\circ}\right)$ with no cutoff of GCR particles. Most measurements have been done on material with a simple composition, often quartz $\left(\mathrm{SiO}_{2}\right)$ or calcite $\left(\mathrm{CaCO}_{3}\right)$.

Several studies have been done at accelerators on production systematics of terrestrial cosmogenic nuclides. Some irradiations were done at the Los Alamos Meson Physics Facility, usually using secondary neutrons near a beam-stop. These irradiations have yielded some production ratios, such as ${ }^{10} \mathrm{Be} /{ }^{14} \mathrm{C} /{ }^{26} \mathrm{Al}$ in $\mathrm{SiO}_{2}$ (Reedy et al. $1994 \mathrm{~b}$ ), and could be used to get relative production rates from pure elements. Some accelerators are also sources of muon beams. Work is also being done on measuring yields of nuclides from fast muons or muons stopping in various targets (Reedy et al. 1994c).

As the ratio of neutrons to protons in the Earth's surface is higher than in most meteorites and lunar samples, cross sections for the production of terrestrial cosmogenic nuclides by energetic neutrons are very important. However, only a few neutron cross sections have been measured for the nuclides 
of interest, mainly at energies below $20 \mathrm{MeV}$. More cross sections are needed for terrestrial cosmogenic nuclides, especially for neutron energies above $20 \mathrm{MeV}$.

Neutron-transport codes, such as the Monte Carlo N-Particle (MCNP) code, can be used to study nuclides made by neutron-capture reactions and have shown that rates for the ${ }^{35} \mathrm{Cl}(\mathrm{n}, \gamma)^{36} \mathrm{Cl}$ reaction depend on the rock's composition and water content. The LAHET Code System (LCS) and similar codes have been used very successfully for studying cosmogenic nuclides in extraterrestrial matter. LCS was recently to study production of nuclides in the Earth (Masarik and Reedy, this workshop).

\section{REFERENCES}

Masarik, J. and Reedy, R. C. 1996 Monte Carlo simulation of in-situ-produced cosmogenic nuclide. Radiocarbon, this issue. Reedy, R. C. et al. 1994a Nuclear Instruments and Methods B92: 335. 1994b Nuclear Instruments and Methods B92: 297.

1994c ICOG-8 Abstracts. U.S. Geological Survey Circular 1107: 262.

\section{WORKSHOP ON SECULAR VARIATIONS IN THE RATES OF PRODUCTION OF COSMOGENIC NUCLIDES ON EARTH: PALEOMAGNETIC AVERAGES OF GEOMAGNETIC LATITUDE}

\section{ROB STERNBERG}

Department of Geosciences, Franklin \& Marshall College, P.O. Box 3003, Lancaster, Pennsylvania 17604 USA

The production rate of cosmogenic nuclides depends on the geomagnetic cutoff rigidity, which in turn depends upon geomagnetic latitude. The geomagnetic dipole moment axis moves over time, one of the characteristic patterns of secular variation. Over the past $300 \mathrm{yr}$, the latitude of the northerly end of the dipole axis has decreased from $c a .83^{\circ} \mathrm{N}$ to $78^{\circ} \mathrm{N}$, while longitude has drifted westward from $320^{\circ} \mathrm{E}$ to $290^{\circ} \mathrm{E}$ (Merrill and McElhinny 1983). On the other hand, a critical assumption of paleomagnetism is the geocentric axial dipole field hypothesis, whereby the magnetic direction at any locality will average over several millennia to that of an axial geocentric dipole.

Data of Ohno and Hamano (1992) were used to model the effect of dipole secular variation on average geomagnetic latitude. This compilation gives average pole positions at $500-\mathrm{yr}$ increments for the past 10,000 yr, based on archaeomagnetic and sediment paleomagnetic data. For several sites on the Earth's surface, the average pole position was integrated back in time from the present to 10,000 yr ago. Differences between geomagnetic and geographic latitudes (here called the latitude difference) were calculated for the time-integrated average pole positions at 500 -yr increments. Averaging from the present back to $1-4$ ka gives a median difference of $1.7^{\circ}$; from $4-7 \mathrm{ka}$, it is $1.4^{\circ}$; from 7-10 ka, it is also $1.4^{\circ}$. A similar analysis was carried out using pole positions of Merrill and McElhinny (1983: Table 4.1) at 100 -yr increments back to $2000 \mathrm{yr}$ BP. Averaging from the present back to $200-800 \mathrm{BP}$ gives a median difference of $4.2^{\circ}$. Thus, for exposure times longer than several centuries, the latitude error is typically $1.5^{\circ}$.

The Laschamp excursion, involving anomalous paleomagnetic directions and intensities, has been observed in some but not all data sets between 30 and $50 \mathrm{ka}$ (Thouveny and Creer 1992). If such an excursion were due to a tilt of the dipole axis, its effect on average geomagnetic latitude could also be calculated. If the pole moves linearly to a latitude of $45^{\circ}$ and back during a 5-ka long excursion (ignoring changes in dipole moment), the integrated average latitude difference is down to $2^{\circ}$ after 50,000 yr; for a short 200-yr excursion (Thouveny and Creer 1992), the difference is down to $2^{\circ}$ after $200 \mathrm{yr}$. 


\title{
REFERENCES
}

Merrill, R. T. and McElhinny, M. W. 1983 The Earth's Magnetic Field. London, Academic Press: 401 p. Ohno, M. and Hamano, Y. 1992 Geomagnetic poles over the past 10,000 years. Geophysical Research Letters 19: 1715-1718. Thouveny, N. and Creer, K. M. 1992 Geomagnetic excursions in the past 60 ka: Ephemeral secular variation figures. Geology 20: $399-402$.

\section{COSMOGENIC CHLORINE-36 PRODUCTION RATES FROM CALCIUM AND POTASSIUM}

\author{
JOHN STONE, ${ }^{1}$ JODIE EVANS, ${ }^{1,2}$ KEITH FIFIELD, ${ }^{2}$ RICHARD CRESSWELL ${ }^{2}$ \\ and GARY ALLAN
}

Advantages of exposure dating with cosmogenic Chlorine- 36 are high ${ }^{36} \mathrm{Cl}$ production rates in a number of common minerals, and the high sensitivity of $\mathrm{AMS} \mathrm{Cl}$ isotopic analyses. A disadvantage is the variety of ${ }^{36} \mathrm{Cl}$-producing reactions-spallation reactions on $\mathrm{K}$ and $\mathrm{Ca}$, muon capture reactions on these elements, and capture (by ${ }^{35} \mathrm{Cl}$ ) of secondary neutrons produced in spallation, muon capture and fast muon interactions. Complications arise through the different latitude, altitude, depth and compositional dependences of these reactions. Also, errors in calibration of any one reaction tend to propagate into calibration of the others. In estimating ${ }^{36} \mathrm{Cl}$ production rates from geological surfaces, our strategy has been to: 1) work with separated minerals—calcite, Ca-feldspar and K-feldspar- to maximize target element abundances (enhancing analytical sensitivity) and $\mathrm{Ca} / \mathrm{Cl}$ and $\mathrm{K} /$ $\mathrm{Cl}$ ratios (enhancing contributions from spallation relative to slow neutron capture); 2) use high altitude sites for calibrating spallation reactions and deep sub-surface samples for calibrating muon reactions; and 3) suppress ${ }^{36} \mathrm{Cl}$ measurement errors and reduce dependence on accurate $\mathrm{Cl}$ analyses by adding $\mathrm{Cl}$ carrier to samples.

Results are summarized below. Quoted uncertainties are $\pm 1 \sigma$ ( $68 \%$ confidence) based on analytical errors and indicated uncertainties in calibration surface ages. Uncertainties refer to production rates at the calibration sites; additional errors in scaling to sea-level and high latitude have not been propagated here. Spallation and muon reactions have been scaled separately using the procedures of Lal (1991: EPSL 104, 424). Latitude corrections are based on effective geomagnetic latitudes $\left(\lambda_{\text {eff }}\right)$ of the calibration sites over their exposure times. Sidereal ages are used for calibration, to avoid errors due to non-linearity in the radiocarbon timescale.

1. Ca Spallation: Our primary calibration is based on Ca-feldspar from the Tabernacle Hill basalt $\left(\mathrm{t}_{\exp }=17.3 \pm 0.5 \mathrm{ka}\right)$, which gives a Ca spallation rate of $152 \pm 5$ atom $(\mathrm{g} \mathrm{Ca})^{-1} \mathrm{a}^{-1}$ at $1445 \mathrm{~m}$, $\lambda_{\text {eff }}=40.9^{\circ}$. Five measurements were made on feldspar from three separate rock samples. Caspallation accounts for $86-88 \%$ of ${ }^{36} \mathrm{Cl}$ in the samples, with $5 \%$ due to ${ }^{40} \mathrm{Ca}\left(\mu^{-}, \alpha\right)^{36} \mathrm{Cl}, 7 \%$ due to $\mathrm{K}$ reactions and $1-2 \%$ due to neutron capture. The equivalent rate at sea level and high latitude is $48.8 \pm 1.7$ atom $(\mathrm{g} \mathrm{Ca})^{-1} \mathrm{a}^{-1}$.

2. Muon Reactions in Calcite: ${ }^{36} \mathrm{Cl}$ measurements on a $20-\mathrm{m}$ profile in calcite marble at Wombeyan in SE Australia $\left(620 \mathrm{~m}, \lambda=34.3^{\circ}\right)$ give a ${ }^{40} \mathrm{Ca}\left(\mu^{-}, \alpha\right)^{36} \mathrm{Cl}$ production rate of 0.011 \pm 0.0013 atom ${ }^{36} \mathrm{Cl}$ per stopped negative muon and a secondary neutron yield of $0.41 \pm 0.1 \mathrm{neu}-$ trons per stopped negative muon in calcite. Assuming a negative muon stopping rate of $175 \mu^{-}$ $\mathrm{g}^{-1} \mathrm{a}^{-1}$ at sea-level and high latitude, the surface production rate for the ${ }^{40} \mathrm{Ca}\left(\mu^{-}, \alpha\right)^{36} \mathrm{Cl}$ reaction is $4.8 \pm 0.5$ atom $\left(\mathrm{g} \mathrm{Ca}^{-1} \mathrm{a}^{-1}\right.$ (i.e., $9 \%$ of total production from $\mathrm{Ca}$ ). The natural calibration avoids the need to know values for muon reaction parameters such as the chemical compound factor and $\alpha$-emission probability. Estimates of these factors are required to apply the results to 
minerals other than calcite, however. Assuming a Fermi-Teller ("z-law") distribution of muon captures between $\mathrm{Ca}, \mathrm{C}$ and $\mathrm{O}$ in calcite, we derive an $\alpha$-emission probability following muon capture of $0.033 \pm 0.004$, well within the range of existing measurements and calculations $(0.004<\mathrm{P} \alpha<0.15)$.

3. ${ }^{36} \mathrm{Cl}$ production from $\mathrm{K}$ : So far only surface samples of $\mathrm{K}$-feldspar have been measured, precluding a breakdown of total production from K (PK) into component reactions. Samples from glacial pavements in the Sierra Nevada, Scotland and Antarctica have been measured. Assuming $\mathrm{t}_{\exp }=13.1 \mathrm{ka}$, samples from the Sierra Nevada give $\mathrm{PK}=1460 \pm 88$ atom $(\mathrm{g} \mathrm{K})^{-1} \mathrm{a}^{-1}$ at 3000 $\mathrm{m}$ and $\lambda_{\text {eff }}=37.4^{\circ}$. Concordant results $\left(\chi^{2} / \mathrm{n}=0.8, \mathrm{n}=10\right.$ measurements $)$ are obtained from samples at 4 sites, at elevations between 3000 and $3600 \mathrm{~m}$ and with chloride concentrations from 10-310 ppm. Reactions on K account for 76-99\% of production in the samples. Consistency between samples with low and high $\mathrm{Cl}$ contents is obtained assuming a surface neutron capture rate of $2450 \mathrm{n} \mathrm{g}^{-1} \mathrm{a}^{-1}$ at $3000 \mathrm{~m}$ and $37.4^{\circ}$, close to the scaled value of Zreda et al. (1991: EPSL 105: 94-109). Assuming 5\% of $\mathrm{K}$ production at sea level is due to muon capture, these data give $\mathrm{PK}=180 \pm 11$ atom $(\mathrm{g} \mathrm{K})^{-1} \mathrm{a}^{-1}$ at sea level and high latitude. Samples from pavements exposed by retreat of Loch Lomond (Y. Dryas) Stage ice $\left(t_{\exp }=11.5 \pm 0.3 \mathrm{ka}\right)$ in Scotland give PK $=313$ \pm 25 atom $(\mathrm{g} \mathrm{K})^{-1} \mathrm{a}^{-1}$ at $520 \mathrm{~m}$ and $\lambda=58.5^{\circ}$. Neutron capture corrections are $18-22 \%$ for these samples. Again assuming $5 \%$ of total $\mathrm{K}$ production due to muon capture, these data give $\mathrm{PK}=$ $189 \pm 15$ atom $(\mathrm{g} \mathrm{K})^{-1} \mathrm{a}^{-1}$ at sea level and high latitude, in excellent agreement with results from the Sierra Nevada. Two samples of K-feldspar from the Trans-Antarctic Mountains $\left(\lambda=77.5^{\circ}\right)$, apparently saturated with ${ }^{36} \mathrm{Cl}$, give production rates of $1350 \pm 50$ atom $(\mathrm{g} \mathrm{K})^{-1} \mathrm{a}^{-1}$ at $2050 \mathrm{~m}$ and $1230 \pm 40$ atom $\left(\mathrm{g} \mathrm{K}^{-1} \mathrm{a}^{-1}\right.$ at $2000 \mathrm{~m}$, with negligible (<2\%) corrections for neutron capture on ${ }^{35} \mathrm{Cl}$. Equivalent rates at sea level, scaled as above, are $\mathrm{PK}=239 \pm 10$ and $227 \pm 8$ atom $(\mathrm{g} \mathrm{K})^{-1} \mathrm{a}^{-1}$. The samples have been measured repeatedly to confirm that the $25 \%$ discrepancy with the scaled values from Scotland and the Sierra Nevada is real and must be accounted for either by the scaling procedure, or secular variation in the cosmic ray flux.

\footnotetext{
${ }^{1}$ Research School of Earth Sciences, Australian National University, Canberra, ACT 0200 Australia

${ }^{2}$ Department of Nuclear Physics, Research School of Physical Sciences and Engineering, Australian National University, Canberra, ACT 0200 Australia
}

\section{TEMPORAL VARIATIONS IN GLOBAL ATMOSPHERIC ${ }^{14} \mathrm{C}$ AND ITS PRODUCTION}

\section{MINZE STUIVER}

University of Washington, Box 351360, Seattle, Washington 98195-1360 USA

The atmospheric radiocarbon record of the past $20,000 \mathrm{yr}$ is an integrated response to climatic, solar and geomagnetic forcing. The time dependencies of the forcing functions play an important role in shaping the atmospheric ${ }^{14} \mathrm{C}$ profile. Geomagnetic forcing manifests itself mainly on millennia time scales, whereas solar forcing is more restricted to decadal and century time intervals. Oceanic thermohaline circulation change (and associated climate perturbation) sufficiently large to induce atmospheric ${ }^{14} \mathrm{C}$ change operates on decadal to millennia time scales.

${ }^{14} \mathrm{C}$ age calibration is needed because conventional ${ }^{14} \mathrm{C}$ dates do not take atmospheric ${ }^{14} \mathrm{C}$ variability into account. Use of our knowledge of forcing factors in carbon reservoir models will generate "hypothetical" calibration curves, but the limitations of our knowledge, especially of solar and oce- 
anic variability, are such that calculated calibration curves lack much of the detail found in measured Holocene tree-ring ${ }^{14} \mathrm{C}$.

The record of ${ }^{14} \mathrm{C}$ change can be extended beyond the interval covered by tree rings by using ${ }^{14} \mathrm{C}$ and $\mathrm{U} / \mathrm{Th}$ dated corals. However, the marine surface waters greatly attenuate production-rate induced ${ }^{14} \mathrm{C}$ variations, and thus the calibration curve extension loses much century-type production rate detail.

\section{DETERMINATION OF ${ }^{36} \mathrm{CI}$ PRODUCTION RATES FROM THE DEGLACIATION HISTORY OF WHIDBEY AND FIDALGO ISLANDS, WASHINGTON}

\section{TERRY SWANSON}

University of Washington, Seattle, Washington 98195 USA

Cosmogenic ${ }^{36} \mathrm{Cl}$ is produced in surface rocks by thermal neutron activation of ${ }^{35} \mathrm{Cl}$, spallation of ${ }^{39} \mathrm{~K}$ and ${ }^{40} \mathrm{Ca}$ and slow negative muon capture by ${ }^{40} \mathrm{Ca}$. Production parameters for the ${ }^{36} \mathrm{Cl}$ isotopic system were refined using the well-constrained deglaciation history of Whidbey and Fidalgo Islands, Washington, USA. Calculated production rates due to spallation are $1770 \pm 121$ atoms ${ }^{36} \mathrm{Cl}$ ( $\mathrm{kg}^{-1}$ rock) (percent $\mathrm{K}_{2} \mathrm{O}^{-1}$ ) $\mathrm{yr}^{-1}$ and $641 \pm 20$ atoms ${ }^{36} \mathrm{Cl}\left(\mathrm{kg}^{-1}\right.$ rock) (percent $\left.\mathrm{Ca}^{-1}\right) \mathrm{yr}^{-1}$. The calculated effective thermal neutron absorption rate is $(3.53 \pm 0.07) \times 10^{5}$ neutrons kg-1 of rock $\mathrm{r}^{-1}$. Production due to muon capture by ${ }^{40} \mathrm{Ca}$ was estimated using previously calculated values scaled to high geomagnetic latitude and sea level.

Consistency between calculated ${ }^{36} \mathrm{Cl}$ ages using the production rates reported here, and independent ${ }^{14} \mathrm{C}$ ages that constrain the timing of deglaciation of the Cordilleran Ice Sheet over three disparate locations, substantiates the validity of the ${ }^{36} \mathrm{Cl}$ production rates for high-latitude $\left(>60^{\circ}\right)$ locations, integrated over the last $\sim 15,200 \mathrm{cal}$ yr. Evaluation of potential sources of error indicate that uncertainty of AMS and total $\mathrm{Cl}$ measurements are the dominant factors controlling the overall uncertainty of the ${ }^{36} \mathrm{Cl}$ ages. Geologic factors such as surface erosion and/or prior exposure history are also important sources of error that were addressed by this study; however, independent testing of the production rates on independent surfaces of known age suggest that these potential problems were minor for the 64 calibration samples.

Analytical uncertainties of $\pm 5-6 \%(1 \sigma)$ for the calibration samples indicate that it should be possible to resolve late-glacial landforms from those of full-glacial age using the ${ }^{36} \mathrm{Cl}$ dating method, providing the analytical uncertainty of AMS and total $\mathrm{Cl}$ measurements is $<5 \%$ and geological problems are accurately constrained. However, without greatly improving the precision of AMS and total $\mathrm{Cl}$ measurements, it is unlikely that the ${ }^{36} \mathrm{Cl}$ dating method will be able to resolve ages of, or correlate landforms associated with, short-term climatic episodes such as the late-glacial Younger Dryas event. 


\title{
RECENT ADVANCES IN DETERMINING ABSOLUTE AND RELATIVE PALEOINTENSITY VARIATIONS OF THE GEOMAGNETIC FIELD
}

\author{
KENNETH L. VEROSUB
}

Department of Geology, University of California, Davis, California 95616 USA

For the past $30 \mathrm{yr}$, the focus in paleomagnetism has been on the direction of the paleomagnetic vector rather than on its intensity. The reason for this "two-dimensional" view of a three-dimensional quantity is that determination of the paleointensity is inherently more complex, more difficult, and less reliable than determination of the paleomagnetic direction. This situation may be changing as new techniques and new instrumentation are brought to bear on these problems.

For determinations of the absolute paleointensity of the geomagnetic field, the standard methodology has, for many years, been the Thellier-Thellier double heating experiment. This approach can be used with material that carries a thermal remanent magnetization, such as lava flows, hearths and pottery. Unfortunately, the Thellier-Thellier experiment is very time-consuming, and the percentage of samples that give unsatisfactory results can be quite high. As a result, the database of absolute paleointensity determinations is still relatively small. Recently, several research groups have tried to develop mineral magnetic screening criteria for identifying, in advance, those samples that were likely to produce satisfactory results in the Thellier-Thellier experiment. Although this work promises to increase the success rate for absolute paleointensity determinations, it does not address another important problem, namely, the available material seldom represents a continuous sampling of the geomagnetic field through time. This problem is particularly acute for studies involving lava flows but it can also arise when archaeological materials are involved.

Sediments, on the other hand, offer the possibility of a continuous record of geomagnetic intensity variations. For sediments, however, the intensity of magnetization depends on the intensity of the geomagnetic field at the time the magnetization was acquired and on several other factors, including the concentration and grain size of the magnetic carriers. Many years ago it was proposed that the relative intensity of the geomagnetic field intensity could be determined with a normalization based on the intensity of a laboratory-induced magnetization. It was soon recognized that too much variation in the size or concentration of the magnetic grains could be a problem, and various selection criteria were proposed. In recent years, a globally consistent picture of relative paleointensity variations is beginning to emerge, at least for the last $250,000 \mathrm{yr}$. In addition, there has been the intriguing suggestion that variations in relative paleointensity over the past four million years are linked to polarity transitions. However, there is still disagreement about the interpretation of significant spatial and temporal variations that are seen in relative paleointensity records over both time scales. In addition, it is not clear whether the absolute and relative paleointensity records are mutually consistent.

With regard to the determination of production rates of cosmogenic nuclides, it is important to recognize that both absolute and relative paleointensity determinations are not easy to make nor simple to interpret, and that the inherent problems and complexities could lead to problems in calculations based upon them. On the other hand, the most important observation may be that geomagnetic intensities during the past $10,000 \mathrm{yr}$ have been somewhat higher than the average for the past $250,000 \mathrm{yr}$. If this conclusion is correct, then temporal and spatial variations that are present over the longer time interval could have had a relatively minor influence on production rates. 